\title{
Examination of Impact of Arsenic Stress on Soil Microbes
}

\author{
Rashida Sultana ${ }^{1}$, Maleeha Umber* ${ }^{1}$, Fareeha Iffat ${ }^{1}$, Shanzah Kiran ${ }^{1}$, \\ Ayesha Khalid ${ }^{1}$ and Mirza Naseer Ahmad ${ }^{2}$ \\ ${ }^{1}$ Department of Botany, Abdus Salaam Research Forum, Nusrat Jahan College Rabwah, Chenab Nagar, Pakistan. \\ ${ }^{2}$ Department of Geography, Faculty of Earth Sciences, Abdus Salaam Research Forum, Nusrat Jahan College \\ Rabwah, Chenab Nagar, Pakistan. \\ *Corresponding Author Email: maleeha.umber@njc.edu.pk \\ Received 18 June 2020, Revised 11 November 2020, Accepted 20 November 2020
}

\begin{abstract}
The research was performed at Botany department, Nusrat Jahan College Rabwah Pakistan to screen stress tolerance level of soil microbes (pseudomonas and penicillium) taken from NARC (National Agricultural Research Centre) Pakistan against different levels of sodium arsenite stress $(1 \mathrm{mg} / \mathrm{L}$ to $10 \mathrm{mg} / \mathrm{L})$. The research was based on completely randomized design. Three drops were applied to microbes grown on CLED (cysteine-, lactose-, and electrolyte-deficient) media to determine zone of inhibition through disk, well and spread method, while control group was without sodium arsenite application. After application of various levels of arsenic stress organisms were incubated for $24 \mathrm{~h}$ at $37^{\circ} \mathrm{C}$. After incubation, zones of inhibition were measured. Our study has shown that both micobes cannot overcome higher levels of arsenic stress because in higher stress petriplates, increased inhibitory zones were observed.
\end{abstract}

Keywords: Pseudomonas, Penicillium, Arsenic, CLED, Soil microbes, Well method, Spread method, Disk method.

\section{Introduction}

Heavy metals are important and required by cells but there elevated concentrations are always toxic for living cells. The concentration of heavy metals inside cell is to be maintained for performing functions properly [1]. Arsenic (As) is the heavy metal that is one of the elements that is causing toxic effects on soil microbes. Environment is constantly being exposed to As contamination through different sources like waste waters of power stations, compounds containing As, and As smelting in industry [2]. Microorganisms when exposed to metallic ions, there small amount of is used as vital nutrients while others, like As with no significant functional activity show toxic effects on microbial cells. Various microorganisms have developed different resistant mechanisms to cope up with toxic levels of As. The As toxicity depends on its different oxidation states. As in trivalent state is much more toxic then other oxidation states [3]. The use of water with high As concentration for irrigation of soils leads to the reduction in overall crop yield like field of rice with empty panicles [4]. Even lower levels of As in soil have harmful effects on morphology and physiology of plants. The most deleterious biochemical effects of As toxicity are the production of reactive oxygen species such as hydrogen peroxide radical, hydroxyl radical, and superoxide radical. Microbes present in soil effect As behaviour in soil by making changes in its chemical speciation. Microorganism's effect solubility, mobility of As by shifting it in its different oxidation states [5]. Higher intensity of heavy 
metals in soils reduces population of microbes, variety and performance [6]. In this study effect of arsenite stress on two microbes were examined. One was a bacteria and the other was fungi.

Pseudomonas is a Gram-negative rod shaped bacteria, measuring $0.5-0.8 \mu \mathrm{m} \quad \mathrm{x} 1-3$ $\mu \mathrm{m}$. Most of the strains are motile have a single polar flagellum which provides them mobility. The nutritional requirements of Pseudomonas are very low. It grows even in clean water. Naturally they form colonies that are small and rough in soil or water. $P$. aeruginosa strains form pigments, the pyocyanin (blue green) and pyoverdine. Pseudomonas species are globally active in aerobic decomposition and biodegradation, and hence play an important role in the carbon cycle. They are well-known for their abilities to degrade compounds which are highly obstinate to other organisms, including aliphatic and aromatic hydrocarbons, fatty acids, insecticides and other environmental pollutants. Studies on the degradation of natural and artificially synthesized compounds by pseudomonas species has been exploited in approaches to solution of environmental pollution problems. P. stutzeri is a strong denitrifier that can be identified by colonies that appear wrinkled, coherent, hard, and of dark brown color due to their high cytochromec content. P. stutzeri is a common soil inhabitant and can also be found in plant materials and in water [7]. Pseudomonas lives in presence of oxygen. It grows on different media at both $42^{\circ} \mathrm{C}$ and $37^{\circ} \mathrm{C}$. Most commonly it colonizes in hospital in respiratory tract of patients. $P$. aeruginosa causes pulmonary and blood stream infections in human [8].

Penicillium is one of the common fungi occurring in a range of habitats, from soil to air, various food products and indoor environments [9]. The size of the colonies varies in the same species, when grown on different media for the same period and at the same temperature, e.g in case of $P$. Brasilianum colonies grown at $25{ }^{\circ} \mathrm{C}$ for 7 days. Mould growth on citrus fruits is a major problem that leads to economic loss. Although many fungal species are outlined to be involved in the decay of citrus products, Penicillium digitatum (green mold) and Penicillium italicum (blue mold) are the main destructive fungal species. Penicillium spp. are common and are present in soil, decaying vegetation and compost, and the air, particularly in temperate zones (forests, grassland and arable soils). It may be found in vineyards and wine cellars, the soil of citrus plantations, among all types of stored seeds, barns, damp hay, dried fruit and fruit juice [10]. "Blue mold" is a term used to report several species of Penicillium that cause decay of fruit crops before harvesting because visible sporulation on infected fruits is of blue-green in colour [11].

As stated by few earlier researches various species of both microbes are used for the decline of effects of As in soil and on plants in altered ways. A research show that penicillium and Aspergillus isolated from rice rhizosphere are potential tool for the mitigation of As contaminated soil [12]. Another research finding describes that resistant strain of Pseudomonas taiwanensis exhibits physiological modifications in heavy metal stress conditions that are positively involved in intercept risk caused by stress[13]. Pseudomonas citronellolis is found to enhance growth rate of chickpea in sois with elevated levels of As [14].

Present research was planned to check the growth response of both soil microbes under different As stress levels because both play a significant role in bio decomposition which in turn adds to soil fertility, providing excellent growth media for crops and plants of 
all types. The findings of previous research are not in accordance of our findings that show that at higher concentrations of As in soil the microbes survival declines. The microbes introduced in soil for eliminating As when deteriorate again cause the addition of metal in soil. As a result soil contaminates and become unfertile for the plants survival and growth rate of mircobes is also effected. If growth and survival rate of soil microbes is being influenced due to arsenic pollution than preventive measures are needed to be taken.

\section{Materials and Methods}

Present research work was conducted at Botany department, Nusrat Jahan College Rabwah Pakistan to determine growth responses of microbes (pseudomonas and penicillium) on exposure to different values of sodium arsenite stress through disc diffusion [15], well diffusion [16] and spread method. For all purpose sterilized apparatus has been used. Both microbes were taken from NARC, Pakistan and were maintained at CLED media. Two to three drops of following concentrations of sodium arsenite $(1 \mathrm{mg} / \mathrm{L}, 2$ $\mathrm{mg} / \mathrm{L}, 3 \mathrm{mg} / \mathrm{L}, 4 \mathrm{mg} / \mathrm{L}, 5 \mathrm{mg} / \mathrm{L}, 6 \mathrm{mg} / \mathrm{L}, 7$ $\mathrm{mg} / \mathrm{L}, 8 \mathrm{mg} / \mathrm{L}, 9 \mathrm{mg} / \mathrm{L}$ and $10 \mathrm{mg} / \mathrm{L}$ ) were given in respective petriplates. Control pteriplates for each method only had organisms grown on CLED media without arsenic.

\section{CLED Media Preparation}

CLED medium was made by mixing $36 \mathrm{~g}$ of solid CLED agar in $1000 \mathrm{~mL}$ distilled water. In order to properly dissolve CLED agar constant heating and stirring was done. Boiled it for $1 \mathrm{~min}$ for proper termination. Cooled at $50^{\circ} \mathrm{C}$ and poured it in sterilized labelled disposable petri plates. Waited for them to solidify except in spread method in which different levels of sodium arsenite were mixed before solidification of media.

\section{Disc Diffusion Method}

Discs made up of filter paper were used for disc diffusion method. Discs were placed in solutions of sodium arsenite of above mentioned concentrations for a specific time to let the concentration of sodium arsenite be properly diffused into discs. After solidification of media plates were labelled and soil microbes were spread on respective labelled plates and afterwards the discs of varying concentrations were placed in the centre of petri plates with the help of forcep in order to give As stress. Then these stress applied petri plates of microbes as well as control petriplates were incubated for $24 \mathrm{~h}$ at $37^{\circ} \mathrm{C}$. At the end of incubation period growth inhibition zones were measured in all plates.

\section{Well Diffusion Method}

Wells were made in solidified media with the help of sterilized cork borer. After well formation in all labelled petriplates both microbes were spread on respective plates and then As stress of different concentrations of sodium arsenite was given dropwise with droper in wells. Then these stress applied microbe's petri plates and control group were incubated for $24 \mathrm{~h}$ at $37^{\circ} \mathrm{C}$. After incubation zones of inhibition were calculated.

\section{Spread Diffusion Method}

In spread diffusion method, sodium arsenite of different amounts was mixed in liquid media. Afterwards upon solidification microbes were spread on media with the help of cotton buds. Then these stress applied microbes' petri plates were incubated for $24 \mathrm{~h}$ at $37^{\circ} \mathrm{C}$. At the end inhibition zones were examined and recorded.

\section{Results and Discussions Disc Diffusion Method}

Results of disc diffusion method portrayed that pseudomonas growth starts 
being effected from $2 \mathrm{mg} / \mathrm{L}$ and growth rate keeps on declining with increment in sodium arsenite stress levels and eventually zone of inhibition reaches its maximum size at 10 $\mathrm{mg} / \mathrm{L}$ and onwards (Fig.1).

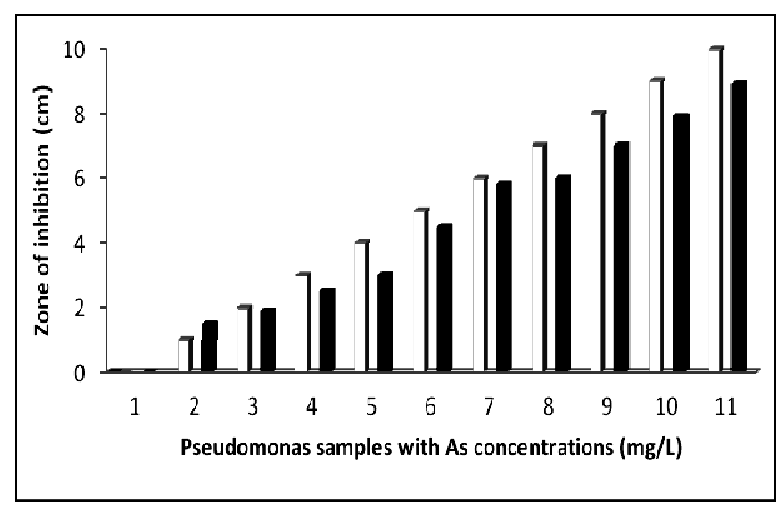

Figure 1. Increasing inhibition zones of pseudomonas with increase in As levels through disc diffusion method

According to results of disc diffusion method disturbance in growth of penicillium starts at $1 \mathrm{mg} / \mathrm{L}$ level of As stress but however to a lot extent this fungus copes up with As stress at this level but further increment in arsenic level to 2, 3, $4 \mathrm{mg} / \mathrm{L}$ and so on causes constantantly increasing decline of penicillium growth (Fig. 2).

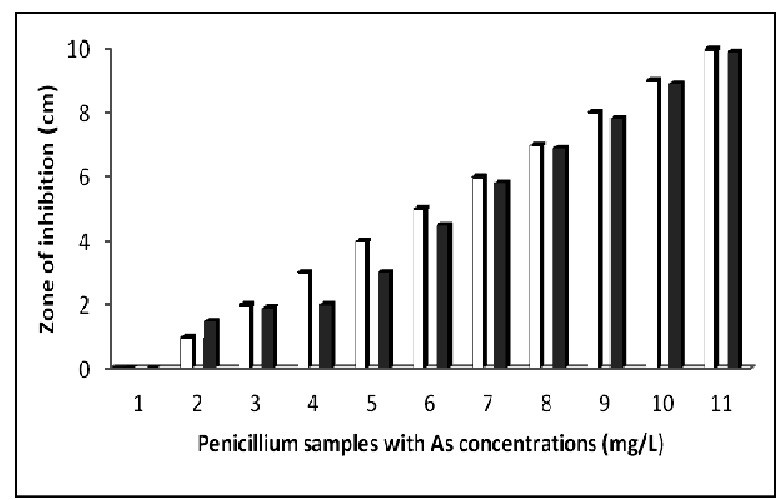

Figure 2. Showing an increase in growth inhibition zones of penicillium through disc diffusion method with increase in As amounts

\section{Well Diffusion Method}

According to Fig. 3 well diffusion method shows that sodium arsenite in liquid form moves in different regions harming pseudomonas present in surroundings. Growth of this fungus keeps on dimminshing parallel to advancement in As contamination levels.

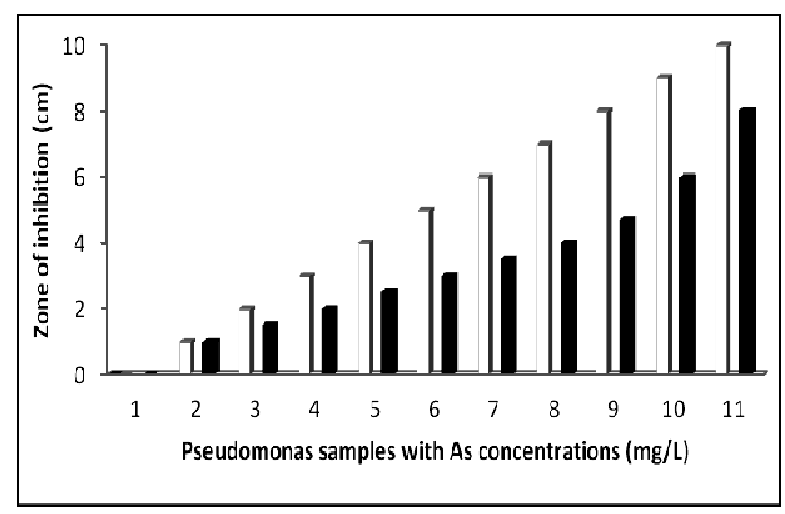

Figure 3. Increasing inhibition zones of pseudomonas with increase in As levels through well diffusion method

Results of well diffusion method show that As contamination does effect penicillium even at very low levels such as $1 \mathrm{mg} / \mathrm{L}$ but such low level effects are negligible in comparison to large scale impacts. Fig. 4 dipicts that growth of penicillium starts retarding from $2 \mathrm{mg} / \mathrm{L}$ level of sodium arsenite stress and as this stress level increases decline in growth rate also enhances.

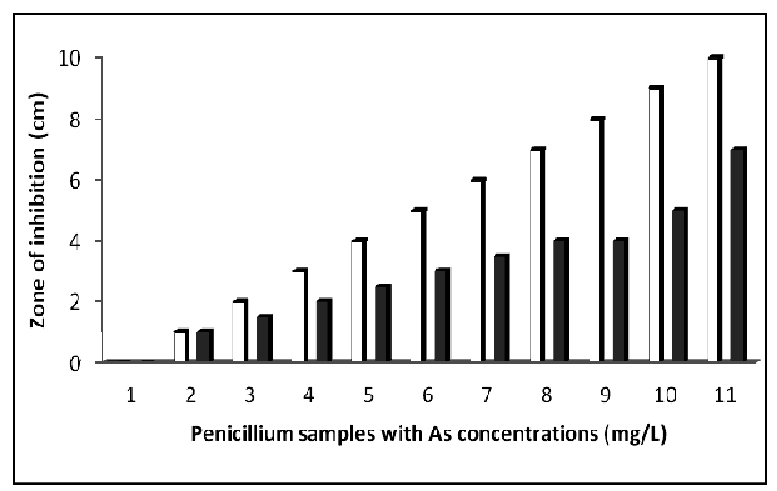

Figure 4. Showing an increase in growth inhibition zones of penicillium through well diffusion method with increase in As amounts

Well diffusion and disc diffusion both are problem causing means. Considering these well and disc methods in natural environment means that if sodium arsenite is entering soil via contaminated water it will diffuse in most regions of soil and those regions which will be 
in direct contact with such water will suffer more with pseudomonas growth inhibition. While if sodium arsenite is present in solid form than those areas of soil which will have more quantity of this compound will be devoid of soil microbe species. Those regions that contain lesser amount of sodium arsenite will slightly influence soil microbes and its colonies.

\section{Spread diffusion method}

Images displayed in Table 1 show that pseudomonas growth starts disturbing from 1 $\mathrm{mg} / \mathrm{L}$ stress level of sodium arsenite though this disturbance is minute at low stress level but as stress levels enhance growth of pseudomonas reduce and ultimately completely declines. This shows that the higher stress level of sodium arsenite not bearable by the microbe and as a result its development is reduced.

In accordance to images of spread method shown in Table 2 it is apparent that penicillium growth rate starts getting inhibited from $1 \mathrm{mg} / \mathrm{L}$ and keeps on inceasing in retard growth activity with increments in sodium arsenite contamination. Among three methods of diffusion i.e. disc, well and spread, third method imparts most drastic impacts on survival of both soil microbes. It means that if even small amount of sodium arsenite in aqueous form is evenly distributed throughout the soil it will cause problems for soil microbes and if this contamination level evenly advances in aqueous state than microbes can completely be declined from effected soil. However, declining trend of soil microbes in response to advancing As pollution is worth pondering because it will reduce soil fertility as decomposing activity will be retarded consequently growth, yield, physiology and many other parameters of plants will be harmed. Harm to plants will impart stress and health issues to secondary consumers. In nutshell entire ecosystem will eventually be disturbed.

Table 1. Images of effect of sodium arsenite on pseudomonas through spread method.

\begin{tabular}{|c|c|c|c|c|c|c|c|c|c|c|}
\hline $\begin{array}{l}\text { Pseudomonas } \\
\text { Method }\end{array}$ & $1 \mathrm{mg} / \mathrm{L}$ & $2 \mathrm{mg} / \mathrm{L}$ & $3 \mathrm{mg} / \mathrm{L}$ & $4 \mathrm{mg} / \mathrm{L}$ & $5 \mathrm{mg} / \mathrm{L}$ & $6 \mathrm{mg} / \mathrm{L}$ & $7 \mathrm{mg} / \mathrm{L}$ & $8 \mathrm{mg} / \mathrm{L}$ & $9 \mathrm{mg} / \mathrm{L}$ & $\begin{array}{c}10 \\
\mathrm{mg} / \mathrm{L}\end{array}$ \\
\hline $\begin{array}{c}\text { Spread } \\
\text { Diffusion }\end{array}$ & & & & & & & & & & \\
\hline
\end{tabular}

Table 2. Images of penicillium influenced by different methods of As contamination of different levels.

\begin{tabular}{|c|c|c|c|c|c|c|c|c|c|c|}
\hline $\begin{array}{l}\text { Penicillium } \\
\text { Method }\end{array}$ & $1 \mathrm{mg} / \mathrm{L}$ & $2 \mathrm{mg} / \mathrm{L}$ & $3 \mathrm{mg} / \mathrm{L}$ & $4 \mathrm{mg} / \mathrm{L}$ & $5 \mathrm{mg} / \mathrm{L}$ & $6 \mathrm{mg} / \mathrm{L}$ & $7 \mathrm{mg} / \mathrm{L}$ & $8 \mathrm{mg} / \mathrm{L}$ & $9 \mathrm{mg} / \mathrm{L}$ & $10 \mathrm{mg} / \mathrm{L}$ \\
\hline $\begin{array}{c}\text { Well } \\
\text { Diffusion }\end{array}$ & & & & & & & & & & \\
\hline $\begin{array}{c}\text { Disc } \\
\text { Diffusion }\end{array}$ & & & & & & & & & $*$ & \\
\hline $\begin{array}{c}\text { Spread } \\
\text { Diffusion }\end{array}$ & & & & & & & & & & \\
\hline
\end{tabular}




\section{Conclusion}

Arsenic pollution adversely affects plants, crops of economic significance and physico chemical properties of soils. Previous researches have proved that micro flora and fauna of soil are also influenced by arsenic contamination. Results of our research are also in accordance to previous findings. According to our results pseudomonas and penicilium can not tolerate higher levels of sodium arsenite contamination. Even lower concentrations of stress of this heavy metal start interrupting survival rate of soil microbes. Preventive measures should be taken to protect soil flora and fauna from arsenic stress. Major cause of elevation of level of heavy metals in soil are uncontrolled and unchecked anthropogenic activities. There should be proper check and balance on all human activities that are not eco friendly. One of the most important way of protecting soil organisms is moving towards organic means for improving soil structure and fertility.

\section{Acknowledgement}

We highly acknowledge National Agricultural Research Centre (NARC) Pakistan.

\section{References}

1. D. H. Nies, Appl. Microbiol. Biotechnol., $51(1999) 730$. doi.org/10.1007/s002530051457

2. M. Hiroki, Soil Sci. Plant Nutr., 39 (1993) 227. doi.org/10.1080/00380768.1993.104169 $\underline{94}$

3. C. Cervantes, G. Ji, J. L. Ramirez and S. Silver, FEMS Microbiol. Rev., 15 (1994) 335.

doi.org/10.1111/j.1574$\underline{6976.1994 . t b 00145 . x}$
4. G. Abbas, B. Murtaza, I. Bibi, M. Shahid, N. K. Niazi, M. I. Khan, M. Amjad, M. Hussain and Natasha, Int. J. Environ. Res. Public Health, 15 (2018) 59.

doi.org/10.3390/ijerph15010059

5. P. K. Srivastava, M. Singh, N. Singh and R. D. Tripathi, J. Bioremed Biodeg., 4 (2013) e137. doi.org/10.4172/2155-6199.1000e137

6. N. Abdu, A. A. Abdullahi and A. Abdulkadir, Environ. Chem. Lett., 15 (2007) 65. https://doi.org/10.1007/s10311-016$\underline{0587-\mathrm{x}}$

7. T. Kenneth, Text book of Bacteriology, 550 (2004) 1

http://textbookofbacteriology.net/pseudo monas.html

8. D. L. Paterson and B. N. Kim, Antimicrob. Drug Resistance, 2 (2009) 811.

doi.org/10.1007/978-1-60327-595-8_9

9. C. M. Visagie, J. Houbraken, J. C. Frisvad, S. B. Hong, C. H. W. Klaassen, G. Perrone, K. A. Seifert, J. Varga, T. Yaguchi and R. A. Samson, Stud Mycol., 78 (2014) 343.

doi.org/10.1016/j.simyco.2014.09.001

10. M. Refai, H. A. El-Yazid and W. Tawakkol, Monograph on the genus penicillium, 51 (2015) 1.

https://www.researchgate.net/publication 1273695076_Monograph_on_the_genus_ Penicillium

11. G. Yin, Y. Zhang, K. Kayla, Pennerman, Wu. Guangxi, S. S. T. Hua, J. Yu, W. M. Jurick, A. Guo and J. W. Bennett, J. Fungi, 3 (2017) 12. doi.org/10.3390/jof3010012

12. L. H. S. Guimarães, F. R. Segura, L. Tonani, M. R. von-Zeska-Kress, J. L. Rodrigues, L. A. Calixto, F. F. Silva and B. L. Batista, J. Environ. Manage., 237 (2019) 179. doi.org/10.1016/j.jenvman.2019.02.060 
13. P. Satapute, M. K. Paidi, M. Kurjogi, and S. Jogaiah, Environ. Pollut., 251 (2019) 555. doi.org/10.1016/j.envpol.2019.05.054

14. A. Adhikary, R. Kumar, R. Pandir, P. Bhardwaj, R. Wusirika and S. Kumar, Plant Physiol. Biochem., 142 (2019) 179 doi.org/10.1016/j.plaphy.2019.07.006
15. A. W. Bauer, W. M. M. Kirby, J. C. Sherris and M. Turck, Am. J. Clin. Pathol., 36 (1966) 493.

16. S. Magaldi, S. Mata-Essayag, C. Hartung de Capriles, C. Perez, M. T. Colella, C. Olaizola and Y. Ontiveros, Int. J. Infect. Dis., 8 (2004) 39. doi: 10.1016/j.ijid.2003.03.002. 